\title{
Comparative Study on Different Drying Methods of Fish Oil Microcapsules
}

\author{
Yuqi Pang, Xu Duan, Guangyue Ren, and Wenchao Liu \\ College of Food \& Bioengineering, Henan University of Science and Technology, Luoyang 471023, China \\ Correspondence should be addressed to Xu Duan; duanxu_dx@163.com
}

Received 26 May 2017; Accepted 10 October 2017; Published 31 October 2017

Academic Editor: Prabhat K. Nema

Copyright (c) 2017 Yuqi Pang et al. This is an open access article distributed under the Creative Commons Attribution License, which permits unrestricted use, distribution, and reproduction in any medium, provided the original work is properly cited.

\begin{abstract}
Microencapsulation is widely used to minimize the oxidation of fish oil products. This study compared the effects of different drying methods, for example, spray drying (SD), freeze drying (FD), and spray freeze drying (SFD) on the microencapsulation of fish oil. Spray drying (SD) is the most common method for producing fish oil microcapsules, and it has low operation cost and short processing time, while the product yield and quality are poor. Freeze drying (FD) can be used to produce oil microcapsules with high quality, but it takes long time and high overall cost for drying. Spray freeze drying (SFD) is a new method for the preparation of microcapsules, which combines the SD and FD processes to obtain high quality powder. The yield of powder reached $95.07 \%$ along with porous structure by SFD. The stability and slow-release property of SFD products were better than those of SD and FD, which showed that SFD improved product storage stability and potential digestibility.
\end{abstract}

\section{Introduction}

Omega-3 polyunsaturated fatty acids ( $\omega$-3-PUFA), especially docosahexaenoic acid (DHA, C22:6 $\omega-3$ ) and eicosapentaenoic acid (EPA, C20:5 $\omega-3$ ), are considered necessary for human health because of some health beneficial effects. The $\omega$-3-PUFA can prevent cardiovascular disease and improve the cardiovascular activity, anti-inflammatory reaction, and development of brain and eye retina in infants and young children $[1,2]$. The main food sources of $\omega$-3-PUFA are fish and fish oil, and particularly fish oil is considered as the most important supplement of $\omega$-3-PUFA [3]. In fact, $\omega$-3 fatty acids biosynthetic pathways are slow in human body [4]; therefore, it could be beneficial to human health by consumption of fish oil which is rich in $\omega$-3 fatty acid [5].

However, the oxidative instability of $\omega$-3-PUFA during storage restricts its use in foods owing to lipid oxidation [6]. At present, the main products of fish oil are soft capsule and oral liquid, but, because of their short storage period, the further processing of fish oil has been limited. Nowadays, encapsulation has appeared to be an essential technique to incorporate such valuable sensitive ingredients into food systems which can be efficiently used to protect food ingredients (i.e., flavors, essential oils, lipids, oleoresins, and colorants) against deterioration, volatile losses, and interaction with other ingredients [7]. As a result, microencapsulation of fish oil could be an alternative method to solve the above issues. It has been reported that microencapsulation of functional foods is an effective approach to achieve the desired attributes of stability, storability, and delivery [8]. Microencapsulation is mainly used to encapsulate a gel, solid, liquid, or gas core by a coating shell [9], which is a promising technique for maintaining the viability of fish oil during the process and covering the smell of fish [10]. Microencapsulation technology could isolate functional oils from deteriorating effects of air, mitigate the evaporation rate of volatile cores, mask the taste or odor of core materials, and isolate reactive core materials from chemical attacks [11]. The key step is the selection of the microencapsulation process and the coating materials in microencapsulation of foods [12, 13].

The spray drying is one of the most frequently used operations for drying of emulsions and slurries containing oils and flavors during microencapsulation process $[14,15]$. Spray drying (SD), which is used to prepare dry, stable, and small volume food material, has characters of low operation cost and short processing time. Nevertheless, due to the high temperature drying strategy during SD process, this drying method was not suitable for the preparation of 
heat sensitive products [16]. Aghbashlo et al. [17, 18] and Ramakrishnan et al. [19] have reported that SD can be used to prepare fish oil microcapsules, and Kalkan et al. [20] used $\mathrm{SD}$ to prepare hazelnut oil microcapsules. But the product quality was not good enough because of high temperature and oxygen stresses. Anwar and Kunz [12] confirmed that although SD only needed a few seconds to produce a desirable size of granules, it had a high chance of lipid degradation by oxidation due to high drying temperature in the SD process. Leung et al. used SD and spray freeze drying (SFD) to produce inhalation phage powders and found that SD powders loss was much higher than the SFD powders during the aerosolization process [21]. Her et al. reported that SD had the advantage of low operation cost as a common technology used in the food industry, while most of flavoring compounds were easily lost during SD operation [14]. Freeze drying (FD) can remove the water by sublimation under vacuum condition to prepare the high quality dried products [22]. However, it takes long time and high overall cost for drying [23]. To avoid drawbacks of both methods, a new method, SFD, is gradually being applied to prepare stable and uniform volume food materials.

SFD combines advantages of SD and FD to obtain fine flavor powders without heat damage, which prevents the powders from agglomeration in turn. SFD is a two-step process, that is, spray freezing followed by freeze drying of the resultant frozen particles in a freeze drier [10]. Ishwarya et al. [24] reported that, compared with other drying technologies, the potential applications in product structure, quality, retention of volatiles, and biologically active compounds of SFD are better. The selection of encapsulation method is governed by important variables, such as the desired size of the microcapsules and the controlled release of oil from microcapsules in foods or in gastrointestinal tract. It was reported that the microcapsule powders by SFD had a uniform particle size, larger specific surface area, and a better porous character than freeze-dried and spray-dried powders. The powders retained their spherical and porous morphology and could be further coated with an enteric food grade biological polymer and conducive to be absorbed $[1,25,26]$. Her et al. [14] reported that SFD combined the SD and FD processes to obtain fine flavor powder without heat damage, which in turn prevented the drying of the agglomerates, while flavor powder produced by the SFD process typically had a larger surface area and higher fine particle fraction than the particles produced by the SD process, so it could be more quickly and easily rehydrated. In addition, the effective embedding capability of SFD powders can mask unpleasant flavor. In conclusion, SFD can be introduced to prepare fish oil microcapsules with better product quality and less oxidation.

Up to date, there is no report about the application of SFD on fish oil microcapsulation. The objective of this research was to compare the performance of spray drying, freeze drying, and spray freeze drying for fish oil microcapsule preparation, and, then, a suitable method of fish oil microcapsule manufacture for different application fields can be suggested.

\section{Materials and Methods}

2.1. Materials. In this study, refined fish oil was purchased from Zebang Biological Technology Co. Ltd. (Xian, Shanxi, China). Acacia gum (food grade) and sodium alginate (food grade) were used to build the microcapsules, and the Tween80 was used as emulsifier. The rest of the reagents used in this study, such as ethanol absolute and light petroleum, were of analytical grade and obtained from the Deen Chemical Reagent Co. Ltd. (Tianjin, China).

2.2. Emulsion Preparation. Two kinds of materials with opposite charge-acacia gum with negative charge and sodium alginate with positive charge-are selected as wall material. Acacia gum, sodium alginate, and Tween- 80 at the ratio of $3: 1: 0.1$ which was determined by the research from Ramakrishnan et al. [19] were added in distilled water, and then the solution was homogenized at $3000 \mathrm{r} / \mathrm{min}$ for $3 \mathrm{~min}$ by a homogenizer (AD500S-H, Onnen Instrument Co., Ltd., Shanghai, China) at $60^{\circ} \mathrm{C}$. Finally, a certain flask proportion of fish oil was added to the solution and the ratio of the core and wall was 1:4, and some water was added to ensure the final solids content to be $15 \%$ which was determined by the research from Li et al. [27], and then it was homogenized at $8000 \mathrm{r} / \mathrm{min}$ for $5 \mathrm{~min}$ by emulsification homogenizer to obtain emulsion liquid reserved.

\subsection{Drying Procedure}

2.3.1. Spray Drying (SD). The pretreated materials were dried by a pressure spray dryer (YC-015, Pilotech Instrument \& Equipment Co., Ltd., Shanghai, China) with two-fluid spray atomization and cocurrent air flow which was $1200 \mathrm{~mm}$ in height, $650 \mathrm{~mm}$ in length, and $500 \mathrm{~mm}$ in width. The emulsion was fed into the chamber through a peristaltic pump at a feed flow rate $\left(1 \times 10^{3} \mathrm{~mL} / \mathrm{h}\right)$. The inlet air temperature was set at $180^{\circ} \mathrm{C}$ while outlet air temperature was $80^{\circ} \mathrm{C}$, and the air flow rate was $35 \mathrm{~m}^{3} / \mathrm{h}$.

2.3.2. Freeze Drying (FD). The emulsion was placed into aluminum plates and frozen at $-25^{\circ} \mathrm{C}$ for $24 \mathrm{~h}$ and then was put into the FD chamber (LGJ-10D, Si Huan Scientific Instrument Factory Co., Ltd., Beijing, China) at the pressure of $20 \mathrm{~Pa}$. During the drying process, the temperature of heat shelf was set as $40^{\circ} \mathrm{C}$ and the cold trap was set at lower than $-50^{\circ} \mathrm{C}$. The frozen emulsion was dried for $36 \mathrm{~h}$.

2.3.3. Spray Freeze Drying (SFD). Figure 1 shows the spray freeze dryer (YC-3000, Pilotech Instrument \& Equipment Co., Ltd., Shanghai, China) used in this study. The emulsion liquid was sprayed through a two-fluid nozzle (nozzle tip lift: $0.5 \mathrm{~mm}$ opening) and a peristaltic pump with a flow rate of $15 \mathrm{~mL} / \mathrm{min}$. The ultimate vacuum pressure can be set at less than $20 \mathrm{~Pa}$ and atomization air pressure can be set from 2 Bar to 5 Bar while it was set at 5 Bar in this study. During this process, spray droplets were frozen while passing through the cryogenic gas. After the spraying process, the samples were treated by FD process. FD process used natural 


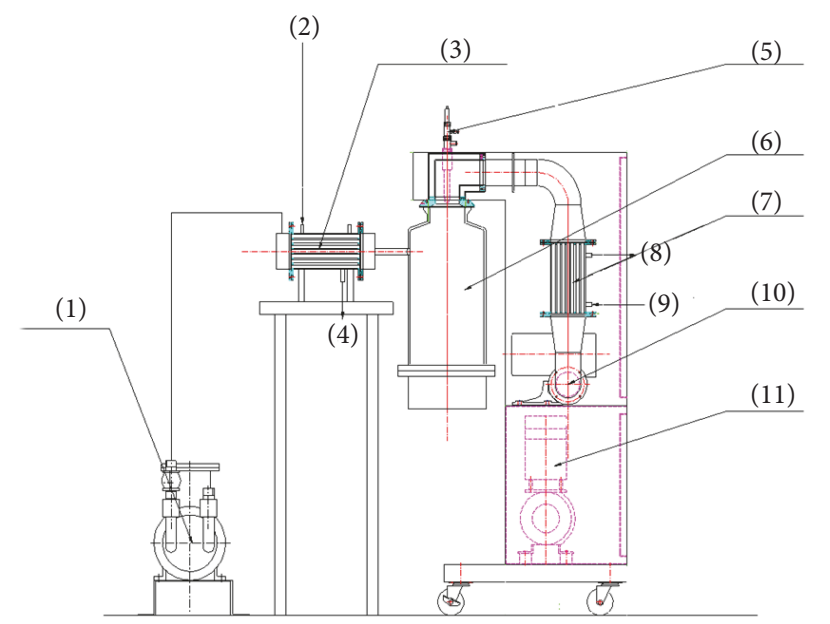

(1) Vacuum pump (5) Atomizer

(9) Coolant inlet

(2) Coolant inlet

(6) Spray freeze drying chamber

(3) Cold trap

(4) Coolant outlet

(7) Heat exchanger

(8) Coolant outlet

FIGURE 1: The schematic diagram of vacuum spray freeze drier.

air heating, and the pressure $(20 \mathrm{~Pa})$ was maintained by a vacuum pump. The cold trap was set at $-65^{\circ} \mathrm{C}$, which was sufficient to condense all vapor generated during FD.

\subsection{Analysis of Sample}

2.4.1. Moisture Content. Moisture content was determined by the gravimetric method. At regular time intervals during the drying processes samples were taken out and dried in the oven for $7-8 \mathrm{~h}$ at $105^{\circ} \mathrm{C}$ until constant weight. Weighing was performed on a digital balance, and then moisture content was calculated. The tests were performed in triplicate.

2.4.2. Drying Yield. The yield of different drying methods was calculated according to formula (1) as follows:

$$
\text { Yield }=\frac{\left(M_{1}-M_{2}\right)}{M_{0}} \times 100 \%,
$$

where $M_{1}$ was the weight (g) of samples after drying; $M_{2}$ was the moisture content (g); and $M_{0}$ was the solids content (g) of emulsion liquid.

2.4.3. Encapsulation Efficiency (EE). The encapsulation efficiency was obtained by determining the total oil content and surface oil content of microcapsules, respectively [28], and was calculated according to formula (2) as follows:

$$
\begin{aligned}
\mathrm{EE}= & \frac{(\text { Total oil content }- \text { Surface oil content })}{\text { Total oil content }} \\
& \times 100 \%
\end{aligned}
$$

Extraction of Total Oil. Ten millilitres of water was added to $2 \mathrm{~g}$ of fish oil microcapsule $\left(M_{1}, \mathrm{~g}\right)$ followed by homogenization for 5 times and the homogenizer was rinsed with ethanol.
The emulsion was sealed by plastic film after $20 \mathrm{~mL}$ ethanol and $20 \mathrm{~mL}$ petroleum ether were added in the beaker $\left(M_{2}, \mathrm{~g}\right)$. The oil was extracted by a magnetic stirrer at $70^{\circ} \mathrm{C}$ for $10 \mathrm{~min}$ followed by centrifuging for $5 \mathrm{~min}$ at $3000 \mathrm{r} / \mathrm{min}$ by a high speed centrifuge (TG16-WS, Xiangyi Laboratory Instrument Development Co., Ltd., Hunan, China). The liquid layer was discarded followed by drying of solid residue and weighing $\left(M_{3}, \mathrm{~g}\right)$. Each treatment was determined in triplicate:

$$
\text { Total oil content }=\frac{\left(M_{3}-M_{2}\right)}{M_{1}},
$$

where $M_{1}$ was the weight (g) of samples; $M_{2}$ was the weight ( $\mathrm{g}$ ) of beaker; and $M_{3}$ was the weight ( $\mathrm{g}$ ) of beaker containing barrier residue $(\mathrm{g})$ after drying.

Extraction of Surface Oil. Twenty millilitres of petroleum ether was added to $2 \mathrm{~g}$ of fish oil microcapsule $\left(M_{1}, \mathrm{~g}\right)$ in an Erlenmeyer flask $\left(M_{4}, \mathrm{~g}\right)$ followed by shaking at $25^{\circ} \mathrm{C}$ for $2 \mathrm{~min}$ and standing for $8 \mathrm{~min}$. The suspension was then filtered through filter paper $\left(M_{5}, \mathrm{~g}\right)$ and the residue was rinsed three times with $15 \mathrm{~mL}$ petroleum ether. The Erlenmeyer flask and filter paper were transferred to an oven (101-2, Kewei Yongxing Instrument Co., Ltd., Beijing, China) and heated at $75^{\circ} \mathrm{C}$ for $6 \mathrm{~h}$ until petroleum ether was completely evaporated and then weighed $\left(M_{6}, g\right)$. Each treatment was determined in triplicate:

$$
\text { Surface oil content }=\frac{\left(M_{1}+M_{4}+M_{5}-M_{6}\right)}{M_{1}},
$$

where $M_{1}$ was the weight (g) of samples; $M_{4}$ was the weight (g) of the Erlenmeyer flask; $M_{5}$ was the weight (g) of filter paper; $M_{6}$ was the total weight (g) after drying.

2.4.4. Color. The color of dried samples was measured using a spectrocolorimeter (Xrite Color i5, X-Rite Inc., MI, USA). The results were expressed as Hunter $L^{*}, a^{*}$, and $b^{*}$, respectively, where $L^{*}$ was the degree of lightness, $a^{*}$ the degree of redness $(+)$ and greenness $(-)$, and $b^{*}$ the degree of yellowness $(+)$ and blueness $(-)$. The Hunter $L^{*}, a^{*}$, and $b^{*}$ values of each treatment were determined in triplicate.

2.4.5. Sensory Evaluation. The sensory evaluation of dried samples was judged by 9 persons who were untrained. They were asked to indicate their preference for each sample, based on the quality attributes of color, appearance, texture, flavor, and overall acceptability. Score was divided into five grades: 9-10 denoted "like very much"; 7-8 "like"; 5-6 "neutral"; 3-4 "dislike"; and 1-2 "dislike very much." They were asked to give their remarks about each of the samples.

2.4.6. Stability. The samples of the microcapsules produced by different drying methods (FD, SD, and SFD) were kept in brown bottle closed containers at $30^{\circ} \mathrm{C}$ for 2 months. Samples were taken to determine the oil stability by detecting the propanal formation every 15 days. A static headspace sampler (G1888 from Agilent Tachnologies, Waldbronn, Germany) 


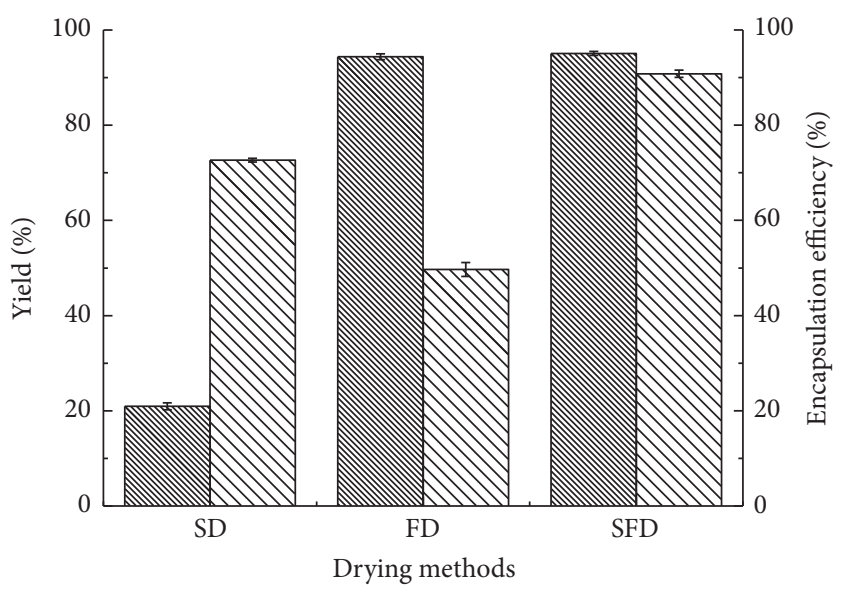

Yield
MIV Encapsulation efficiency

FIGURE 2: The productivity and encapsulation efficiency of different drying methods of fish oil microcapsules.

coupled to a gas chromatograph (HP 6890 from HewlettPackard, Waldbronn, Germany) was used to determine the propanal content of the microcapsules [15].

2.4.7. Scanning Electron Microscopy. The fish oil microcapsules with different treatments were sprinkled onto a two-sided adhesive tape and sputter-coated with gold in a sputter coater. The microstructural properties of the fish oil microcapsules was observed with a Quanta-250 feg scanning electron microscope (FEI Co., Eindhoven, Netherlands) at an accelerating voltage of $10 \mathrm{kV}$.

2.4.8. Slow-Release Property. The fish oil microcapsule was added to $100 \mathrm{~mL}$ simulated gastric fluid $(\mathrm{pH} \mathrm{1)}$ for $2 \mathrm{~h}$ in a constant temperature oscillator with $90 \mathrm{r} / \mathrm{min}$ at $37^{\circ} \mathrm{C}$, which was followed by transferring into simulated intestinal fluid ( $\mathrm{pH}$ 7.1) that contained $0.025 \mathrm{~mol} / \mathrm{L} \mathrm{Na} \mathrm{NPO}_{4}$ and $0.025 \mathrm{~mol} / \mathrm{L} \mathrm{KH}_{2} \mathrm{PO}_{4}$. The released fish oil was extracted and weighed while the release rate was calculated.

2.5. Statistical Analysis. Analysis of variance and the test of mean comparison, according to Tukey's honestly significant difference, were conducted at the level of significance of 0.05 . The statistical software SPSS (version 10.0) for Windows was used for the analysis.

\section{Results and Discussion}

3.1. Characteristics of SFD. Figure 2 shows the yield and encapsulation efficiency of the products obtained by SD, FD, and SFD, respectively. It was found that the yields of SFD (95.07\%) and FD (94.39\%) were close and far greater than that of SD $(20.93 \%)$. The yield of FD and SFD showed no significant difference $(P>0.05)$. The possible reason was that SD underwent higher temperature resulting in part of products lost through the exhaust system and some of products wall sticking during the liquid drop was heated to evaporate. In comparison, SFD and FD could effectively avoid this phenomenon because of lower drying temperature. On the other hand, the encapsulation efficiency of SFD reached $90.80 \%$, while that of FD and SD was $49.7 \%$ and $72.64 \%$, respectively. The encapsulation efficiency of SD was higher than that of Aghbashlo et al. [18] and lower than that of Aghbashlo et al. [29] which may be related to the changes in selection of wall materials and the application of different analytical methods of SFD atomized the emulsion into small droplets under the condition of negative pressure, which promoted the embedment process. Thus, it can be concluded that SFD ensured the highest yield and encapsulation efficiency than SD and FD.

For color of the fish oil microcapsules, $L^{*}$ value exhibits the brightness of sample, and higher $L^{*}$ means brighter color, which implies the product can obtain a good commodity value. As shown in Table 1 , it was found that $L^{*}$ value of SD fish oil microcapsules was much lower than the others. This meant SD samples have a darker color than that of the other two methods because high processing temperature could lead to browning effects. It was observed that there was significant difference between the $L^{*}$ values of SFD and FD products $(P \leqq 0.05)$. The sensory value of FD was also lower than that of SFD because FD powder was irregular in structure and had a large surface area [12]. The moisture content of three samples was similar, but when the three samples were exposed to air for a period of time to observe their mobility, it was found that FD powder had stronger moisture absorption, and the SD powder was easy to agglomerate, while the SFD powder can better maintain the original state. The moisture content of SD powder in the study of Aghbashlo et al. [18] was slightly lower than this study, and the possible reason was the difference of feed flow rate. The higher feed flow rate $\left(1 \times 10^{3} \mathrm{~mL} / \mathrm{h}\right)$ in this study reduced the contact time between the emulsion and the hot air that made the emulsion not fully dried, which resulted in the higher moisture content. Therefore, it can be concluded that SFD can ensure good appearance and product quality. Moreover, as shown in Table 1, compared to FD, SFD greatly reduced drying time.

3.2. Slow-Release Property. Figure 3 shows slow-release curves of various samples. It was found that the slow-release property of SFD was much higher than that of SD and FD. The microcapsules exhibited fast release rate of $27.2 \%$ within the first $1 \mathrm{~h}$, and then the release rate reached about $67.2 \%$ within $8 \mathrm{~h}$. The slow release indicated release of the fish oil from the core of microcapsules. The slow-release rate of FD products was the lowest, which was related to the irregular structure of FD samples, and the thickness of the wall materials was not uniform. As a result, the fish oil was difficult to release from the pore of wall. It was reported that microcapsules released fish oil through diffusion rather than dissolution of the shell material [8]. The release rate of SFD samples was $84.2 \%$ within $12 \mathrm{~h}$, which indicated that the release rate of SFD products was higher. This property was conducive to the absorption of the intestines. The slow-release rate of SD products also increased fast in the 
TABLE 1: Effect of different drying methods on color, sensory value, moisture content, and drying time of fish oil microcapsules.

\begin{tabular}{|c|c|c|c|c|c|c|}
\hline Drying method & $L^{*}$ & $a^{*}$ & $b^{*}$ & Sensory value & Moisture content & Drying time \\
\hline FD & $92.98 \pm 0.05^{\mathrm{b}}$ & $0.90 \pm 0.02^{\mathrm{b}}$ & $8.20 \pm 0.01^{b}$ & $7.13 \pm 0.08^{c}$ & $4.05 \pm 0.03^{\mathrm{a}}$ & $36 \pm 1.0 \mathrm{~h}$ \\
\hline SD & $66.06 \pm 0.01^{c}$ & $12.24 \pm 0.02^{\mathrm{a}}$ & $20.30 \pm 0.06^{\mathrm{a}}$ & $7.94 \pm 0.14^{\mathrm{b}}$ & $3.60 \pm 0.06^{\mathrm{b}}$ & $2.0 \pm 0.5 \mathrm{~h}$ \\
\hline SFD & $95.33 \pm 0.01^{\mathrm{a}}$ & $0.40 \pm 0.03^{c}$ & $1.64 \pm 0.01^{\mathrm{c}}$ & $9.54 \pm 0.04^{\mathrm{a}}$ & $3.38 \pm 0.09^{b}$ & $24 \pm 1.5 \mathrm{~h}$ \\
\hline
\end{tabular}

${ }^{*}$ Different letters indicated a significant difference $(P \leqq 0.05)$ in a column.

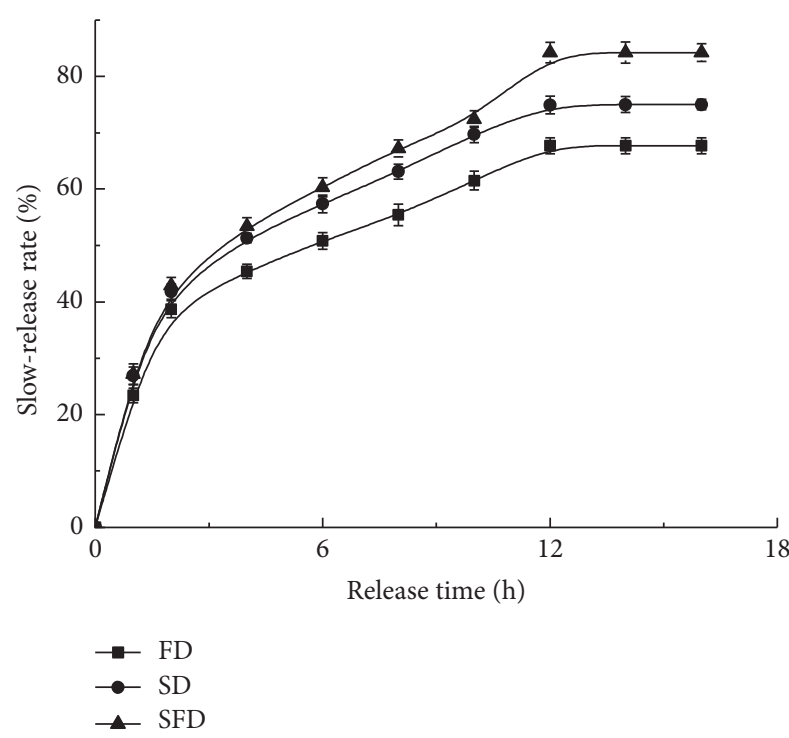

FIGURE 3: Release profile of fish oil microcapsules by different drying methods.

early stage, and then the curve exhibited a gentle trend. The maximum slow-release rate of SD was $75 \%$.

3.3. Stability. Propanal is one of the main volatile compounds generated during the oxidative decomposition of omega-3 fatty acids and it has been recommended to evaluate the oxidation stability of foods that are rich in this type of fatty acids [19].

As shown in Figure 4, at the beginning of this process, the propanal contents of the three kinds of microcapsules were all close to $11 \mathrm{mg} / \mathrm{kg}$. During the first 15 days, the propanal content had a fast growth trend, particularly the FD powder, which had the highest growth rate. Then the growth rate was slowed down slightly, and it tended to be stable after 30 days, which implied almost no subsequent oxidation proceeding. It was found that the propanal content of SFD products was lower than that of SD and FD samples. The possible reason was that the propanal content was related to surface oil content and moisture content. The surface oil content of FD and SD samples was relatively high resulting in a high propanal content. A number of studies have been reported on the oxidative stability of microencapsulated fish oil obtained either by SD or by FD, and the results were inconsistent $[30,31]$. These inconsistent results may be due to changes in conditions of storage and different analytical methods. As a result, SFD could ensure fish oil microcapsules with good stability.

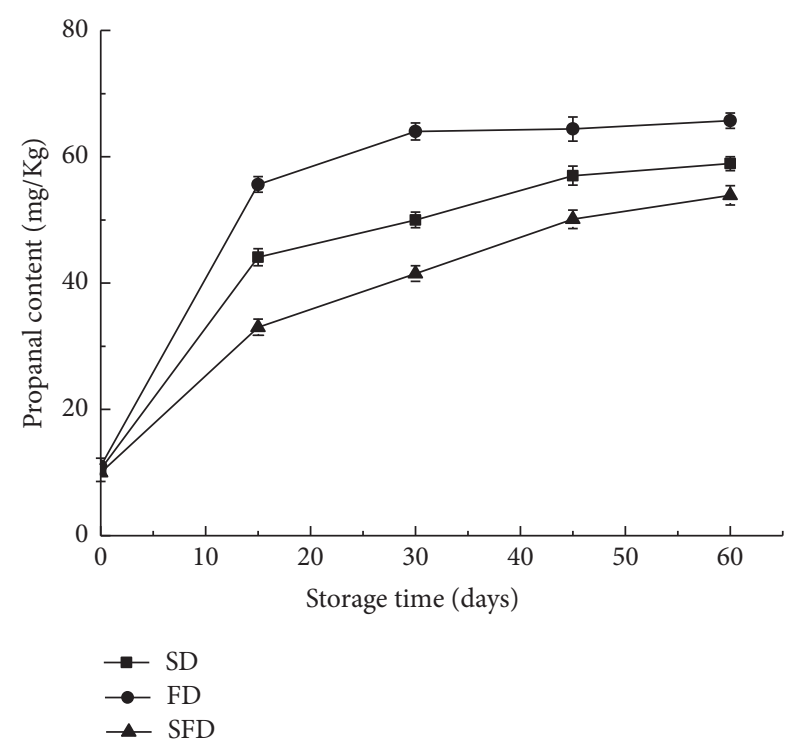

FIGURE 4: The relationship between the storage time and propanal content of fish oil microcapsules by different drying methods.

3.4. Scanning Electron Microscopy. Microcapsule's microstructure and morphology are important to determine their stability, functionality, and flowability [32]. Figure 5 shows the scanning electron microscopy (SEM) images of fish oil microcapsules obtained by different drying methods (SD, FD, and SFD) in order to investigate the surface morphology and microstructure. As shown in Figures 5(a) and 5(b), SFD sample exhibited a clearer porous structure. The porous structure was possibly formed by cavities left from ice crystals or air bubbles retained during the freezing [33]. As water was removed by sublimation during the freeze drying process, the SFD could obtain a porous structure [21]. The image showed the microcapsules of SFD powders had spherical shape and porous surface structure. From Figures 5(b), 5(c), and 5(d), it was found that the microstructure of SD was similar to that of SFD with spherical shape structure but had smooth surface and occurrence of dents and cracks was less, which was similar to the spray granulation (SG) powder done by Anwar et al. [32]. Aghbashlo et al. [34] reported that the microcapsules produced by SD were almost spherical in shape and had a slightly smooth surface without any particle expansion, which was consistent with the results of this study. FD microcapsules had porous surface, but their structure was highly heterogeneous. The reason for the difference of microstructure between FD and SFD was the spray drying process of SFD, which can spray the emulsion liquid to 


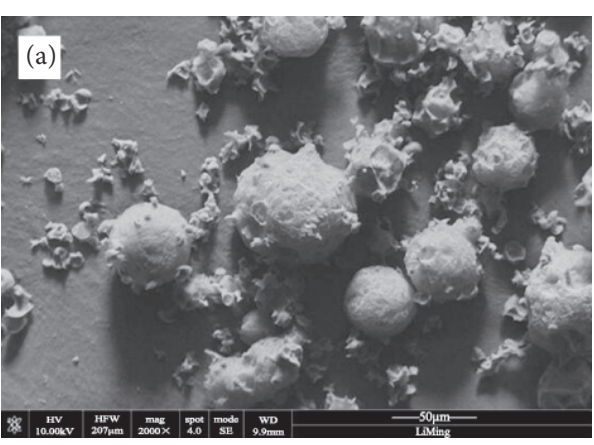

(a)

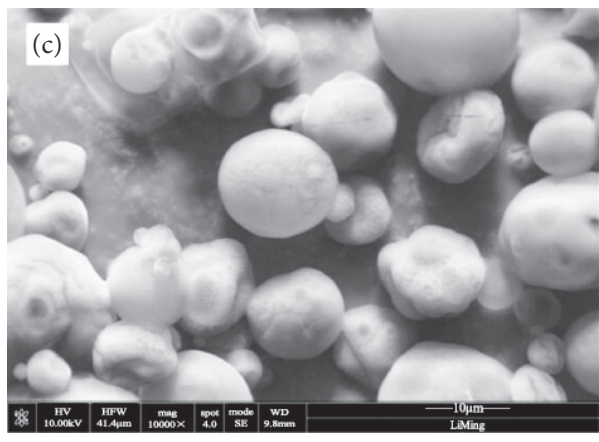

(c)

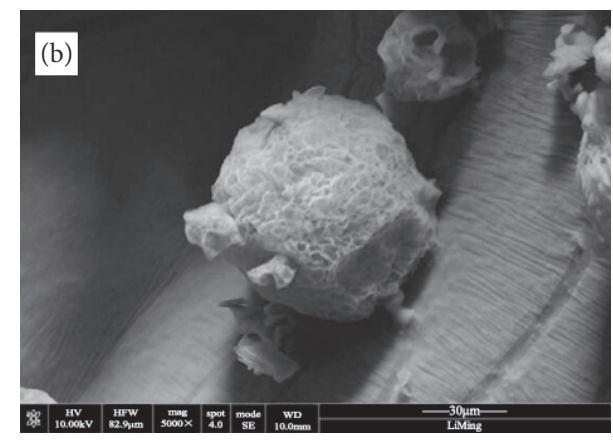

(b)

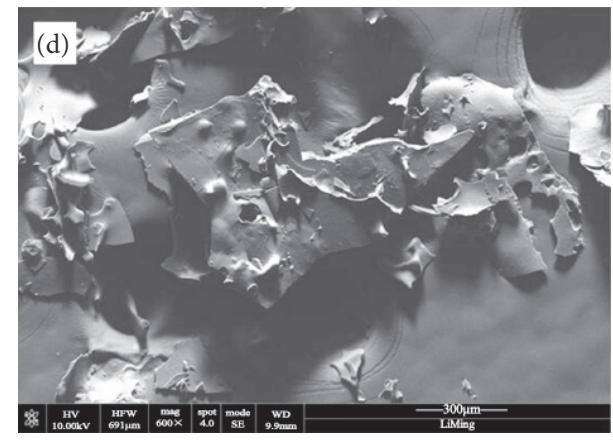

(d)

FIGURE 5: Comparison of the morphology of (a) spray-freeze-dried (2000x); (b) spray-freeze-dried (5000x); (c) spray-dried (10000x); and (d) freeze-dried (600x) fish oil microcapsule.

spheroid. Anwar et al. [32] pointed that the absence of cracks is critically important to wall functionality in limiting fish oil deterioration or oxidation during storage. Therefore, SD and SFD can effectively avoid the deterioration and oxidation of fish oil. In conclusion, SFD produced high quality fish oil microcapsules.

\section{Conclusions}

Freeze drying fish oil microcapsule takes long time and high overall cost for drying. Spray drying has low operation cost and short processing time, while the yield and quality of products are poor under the experimental conditions of this study. Spray freeze drying can replace conventional freeze drying and microcapsule powders produced by SFD have a uniform particle size, large specific surface area, and a great porous character. In addition, SFD improves the slow-release effect and storage stability of the products, and it combines the SD and FD processes to obtain higher quality powder and reduces the drying time.

\section{Conflicts of Interest}

The authors declare that they have no conflicts of interest.

\section{Acknowledgments}

The authors acknowledge that this project was financially supported by the National Natural Science Foundation of
China under Contract no. 31671907 and National Key R\&D Program of China under Contract no. 2017YFD0400900. The authors also acknowledge the support of the Program for Science and Technology Innovation Talents in Universities of Henan Province, no. 14HASTIT023, and the support of the Program for Science and Technology Innovation Team in Universities of Henan Province, no. 16IRTSTHN009.

\section{References}

[1] C. Encina, C. Vergara, B. Giménez, F. Oyarzún-Ampuero, and P. Robert, "Conventional spray-drying and future trends for the microencapsulation of fish oil," Trends in Food Science \& Technology, vol. 56, pp. 46-60, 2016.

[2] P. J. García-Moreno, K. Stephansen, J. Van Der Kruijs et al., "Encapsulation of fish oil in nanofibers by emulsion electrospinning: Physical characterization and oxidative stability," Journal of Food Engineering, vol. 183, pp. 39-49, 2016.

[3] A. Jeyakumari, G. Janarthanan, M. K. Chouksey, and G. Venkateshwarlu, "Effect of fish oil encapsulates incorporation on the physico-chemical and sensory properties of cookies," Journal of Food Science and Technology, vol. 53, no. 1, pp. 856863, 2016.

[4] I. Peinado, W. Miles, and G. Koutsidis, "Odour characteristics of seafood flavour formulations produced with fish by-products incorporating EPA, DHA and fish oil," Food Chemistry, vol. 212, pp. 612-619, 2016.

[5] L. Sanguansri, P. Udabage, S. Bhail et al., "Microencapsulated Fish Oil Powder Formulation with Improved Resistance to Oil 
Leakage During Powder Compression," Journal of the American Oil Chemists' Society, vol. 93, no. 5, pp. 701-710, 2016.

[6] P. J. García-Moreno, A. Guadix, E. M. Guadix, and C. Jacobsen, "Physical and oxidative stability of fish oil-in-water emulsions stabilized with fish protein hydrolysates," Food Chemistry, vol. 203, pp. 124-135, 2016.

[7] S. Shamaei, A. Kharaghani, S. S. Seiiedlou, M. Aghbashlo, F. Sondej, and E. Tsotsas, "Drying behavior and locking point of single droplets containing functional oil," Advanced Powder Technology, vol. 27, no. 4, pp. 1750-1760, 2016.

[8] S. Chatterjee and Z. M. A. Judeh, "Impact of encapsulation on the physicochemical properties and gastrointestinal stability of fish oil," LWT- Food Science and Technology, vol. 65, pp. 206-213, 2016.

[9] A. Ghaemi, A. Philipp, A. Bauer, K. Last, A. Fery, and S. Gekle, "Mechanical behaviour of micro-capsules and their rupture under compression," Chemical Engineering Science, vol. 142, pp. 236-243, 2016.

[10] R. Rajam and C. Anandharamakrishnan, "Spray freeze drying method for microencapsulation of Lactobacillus plantarum," Journal of Food Engineering, vol. 166, pp. 95-103, 2015.

[11] S. Shamaei, S. S. Seiiedlou, M. Aghbashlo, and H. Valizadeh, "Mathematical modeling of drying behavior of single emulsion droplets containing functional oil," Food and Bioproducts Processing, vol. 101, pp. 100-109, 2017.

[12] S. H. Anwar and B. Kunz, "The influence of drying methods on the stabilization of fish oil microcapsules: Comparison of spray granulation, spray drying, and freeze drying," Journal of Food Engineering, vol. 105, no. 2, pp. 367-378, 2011.

[13] P. K. Binsi, N. Nayak, P. C. Sarkar et al., "Structural and oxidative stabilization of spray dried fish oil microencapsulates with gum arabic and sage polyphenols: Characterization and release kinetics," Food Chemistry, vol. 219, pp. 158-168, 2017.

[14] J.-Y. Her, M. S. Kim, M. K. Kim, and K.-G. Lee, "Development of a spray freeze-drying method for preparation of volatile shiitake mushroom (Lentinus edodes) powder," International Journal of Food Science \& Technology, vol. 50, no. 10, pp. 2222-2228, 2015.

[15] S. Shamaei, S. S. Seiiedlou, M. Aghbashlo, E. Tsotsas, and A. Kharaghani, "Microencapsulation of walnut oil by spray drying: effects of wall material and drying conditions on physicochemical properties of microcapsules," Innovative Food Science and Emerging Technologies, vol. 39, pp. 101-112, 2017.

[16] J.-Y. Her, M. S. Kim, and K.-G. Lee, "Preparation of probiotic powder by the spray freeze-drying method," Journal of Food Engineering, vol. 150, pp. 70-74, 2015.

[17] M. Aghbashlo, H. Mobli, S. Rafiee, and A. Madadlou, "An artificial neural network for predicting the physiochemical properties of fish oil microcapsules obtained by spray drying," Food Science and Biotechnology, vol. 22, no. 3, pp. 677-685, 2013.

[18] M. Aghbashlo, H. Mobli, A. Madadlou, and S. Rafiee, "Influence of Wall Material and Inlet Drying Air Temperature on the Microencapsulation of Fish Oil by Spray Drying," Food and Bioprocess Technology, vol. 6, no. 6, pp. 1561-1569, 2013.

[19] S. Ramakrishnan, M. Ferrando, L. Aceña-Muñoz, M. Mestres, S. De Lamo-Castellví, and C. Güell, "Influence of Emulsification Technique and Wall Composition on Physicochemical Properties and Oxidative Stability of Fish Oil Microcapsules Produced by Spray Drying," Food and Bioprocess Technology, vol. 7, no. 7, pp. 1959-1972, 2014.

[20] F. Kalkan, S. K. Vanga, R. Murugesan, V. Orsat, and V. Raghavan, "Microencapsulation of hazelnut oil through spray drying," Drying Technology, vol. 35, no. 5, pp. 527-533, 2017.
[21] S. S. Y. Leung, T. Parumasivam, F. G. Gao et al., "Production of Inhalation Phage Powders Using Spray Freeze Drying and Spray Drying Techniques for Treatment of Respiratory Infections," Pharmaceutical Research, vol. 33, no. 6, pp. 1486-1496, 2016.

[22] J. Barbosa, S. Borges, M. Amorim et al., "Comparison of spray drying, freeze drying and convective hot air drying for the production of a probiotic orange powder," Journal of Functional Foods, vol. 17, pp. 340-351, 2015.

[23] C. Chranioti, S. Chanioti, and C. Tzia, "Comparison of spray, freeze and oven drying as a means of reducing bitter aftertaste of steviol glycosides (derived from Stevia rebaudiana Bertoni plant) - Evaluation of the final products," Food Chemistry, vol. 190, pp. 1151-1158, 2016.

[24] S. P. Ishwarya, C. Anandharamakrishnan, and A. G. F. Stapley, "Spray-freeze-drying: A novel process for the drying of foods and bioproducts," Trends in Food Science \& Technology, vol. 41, no. 2, pp. 161-181, 2015.

[25] T. Okuda, Y. Suzuki, Y. Kobayashi et al., "Development of biodegradable polycation-based inhalable dry gene powders by spray freeze drying," Pharmaceutics, vol. 7, no. 3, pp. 233-254, 2015.

[26] D. Semyonov, O. Ramon, Z. Kaplun, L. Levin-Brener, N. Gurevich, and E. Shimoni, "Microencapsulation of Lactobacillus paracasei by spray freeze drying," Food Research International, vol. 43, no. 1, pp. 193-202, 2010.

[27] J. Li, S. Xiong, F. Wang, J. M. Regenstein, and R. Liu, "Optimization of Microencapsulation of Fish Oil with Gum Arabic/Casein/Beta-Cyclodextrin Mixtures by Spray Drying," Journal of Food Science, vol. 80, no. 7, pp. C1445-C1452, 2015.

[28] P. Pourashouri, B. Shabanpour, S. H. Razavi, S. M. Jafari, A. Shabani, and S. P. Aubourg, "Impact of Wall Materials on Physicochemical Properties of Microencapsulated Fish Oil by Spray Drying," Food and Bioprocess Technology, vol. 7, no. 8, pp. 2354-2365, 2014.

[29] M. Aghbashlo, H. Mobli, A. Madadlou, and S. Rafiee, "The correlation of wall material composition with flow characteristics and encapsulation behavior of fish oil emulsion," Food Research International, vol. 49, no. 1, pp. 379-388, 2012.

[30] W. Kolanowski, M. Ziolkowski, J. Weißbrodt, B. Kunz, and G. Laufenberg, "Microencapsulation of fish oil by spray drying Impact on oxidative stability. Part 1," European Food Research and Technology, vol. 222, no. 3-4, pp. 336-342, 2006.

[31] S. Drusch, Y. Serfert, and K. Schwarz, "Microencapsulation of fish oil with n-octenylsuccinate-derivatised starch: flow properties and oxidative stability," European Journal of Lipid Science and Technology, vol. 108, no. 6, pp. 501-512, 2006.

[32] S. H. Anwar, J. Weissbrodt, and B. Kunz, "Microencapsulation of fish oil by spray granulation and fluid bed film coating," Journal of Food Science, vol. 75, no. 6, pp. E359-E371, 2010.

[33] Y. Zhang, C. Tan, S. Abbas, K. Eric, S. Xia, and X. Zhang, "Modified SPI improves the emulsion properties and oxidative stability of fish oil microcapsules," Food Hydrocolloids, vol. 51, pp. 108-117, 2015.

[34] M. Aghbashlo, H. Mobli, A. Madadlou, and S. Rafiee, "Fish oil microencapsulation as influenced by spray dryer operational variables," International Journal of Food Science \& Technology, vol. 48, no. 8, pp. 1707-1713, 2013. 

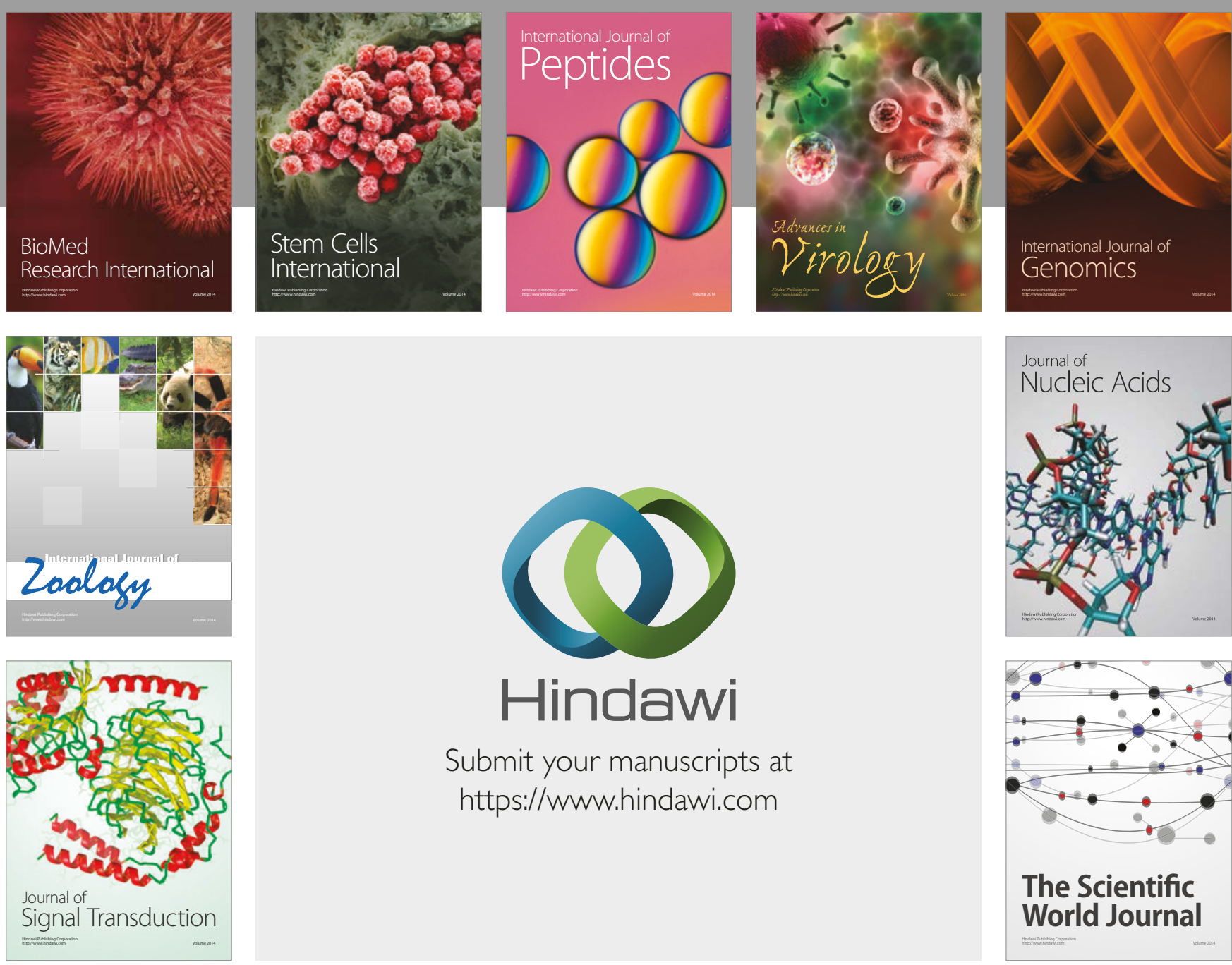

Submit your manuscripts at

https://www.hindawi.com
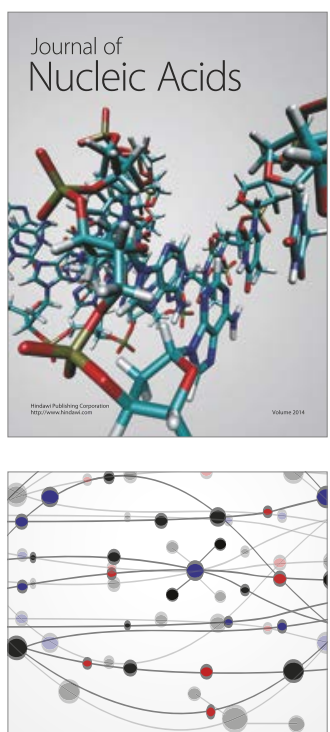

The Scientific World Journal

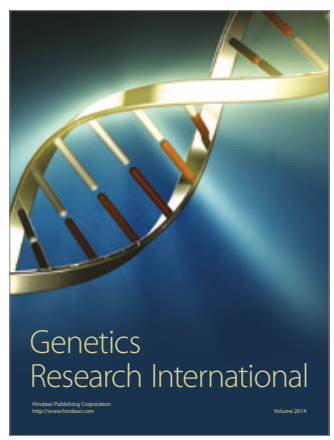

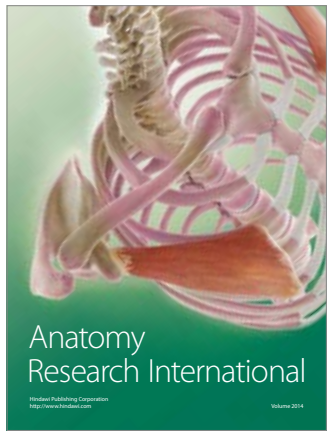

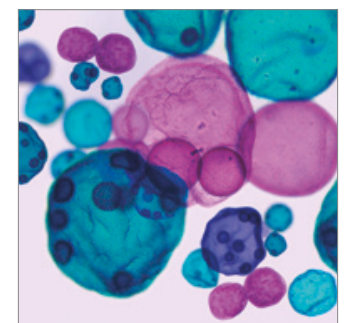

International Journal of Microbiology
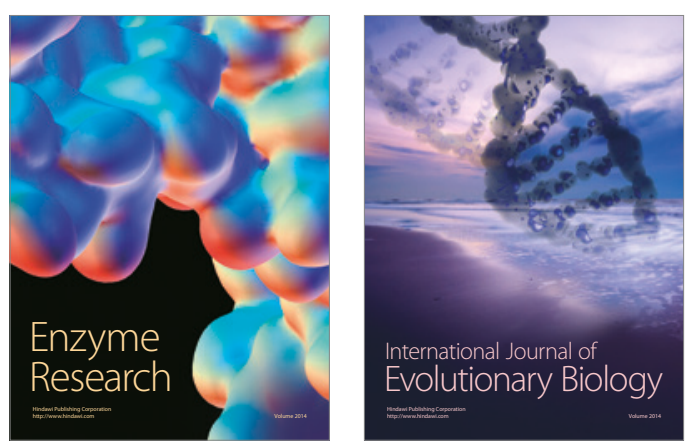
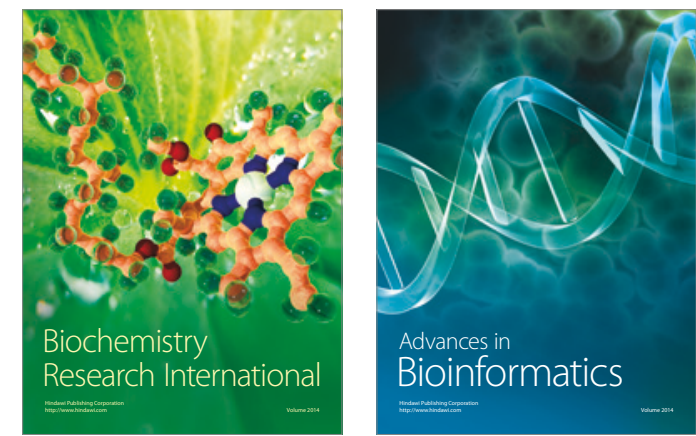

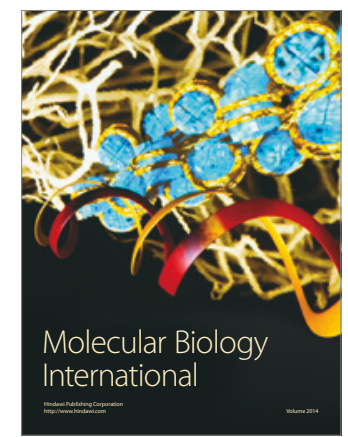

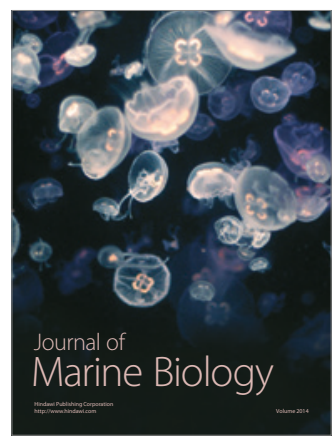

